\title{
Spatial distribution and determinants of household iodized salt utilization in Ethiopia: a spatial and multilevel analysis of Ethiopian demographic and Health survey
}

Yigizie Yeshaw ${ }^{1,2^{*}}$ D, Adugnaw Zeleke Alem², Getayeneh Antehunegn Tesema², Achamyeleh Birhanu Teshale ${ }^{2}$, Alemneh Mekuriaw Liyew ${ }^{2}$ and Ayenew Kassie Tesema ${ }^{3}$

\begin{abstract}
Background: lodine deficiency disorder is a significant public health problem, affecting both developed and developing nations worldwide. It is associated with poor body growth and irreversible mental retardation. However, little is known about the spatial distribution and determinants of household iodized salt utilization in Ethiopia. Therefore, this study aimed to explore the spatial distribution and determinants of iodized salt utilization at national level.

Methods: Ethiopian Demographic and Health Survey 2016 data was used to investigate the spatial distribution and determinants of household iodized salt utilization in Ethiopia. ArcGIS 10.6 and SaTScan ${ }^{\text {TM }}$ version 9.6 software were used to explore the spatial distribution and detect significant clusters, respectively. The odds ratio with its 95\% confidence interval (Cl) was determined for potential determinants included in the multivariable multilevel logistic regression model.

Results: Household iodized salt utilization was spatially clustered in Ethiopia (Moran's Index =0.076, $p$-value $=0.01$ ). The significant hotspot areas with high iodized salt utilization were located in Benishangul, Amhara, Gambella, Tigray and Northwest Oromia regions. Significant cold spot areas (areas with low iodized salt utilization) were found in Somali, and East Afar regions. Those households with higher education level ((Adjusted Odds Ratio $[A O R]=1.49$, $95 \% \mathrm{Cl}=1.14-1.93)$, high community level education $(A O R=1.51,95 \% \mathrm{Cl}=1.03-2.20)$, middle wealth index ( $\mathrm{AOR}=$ $1.31,95 \% \mathrm{Cl}=1.04-1.65)$ and high community media exposure $(\mathrm{AOR}=1.52,95 \% \mathrm{Cl}=1.07-2.17)$ had higher odds of iodized salt utilization.

\footnotetext{
* Correspondence: yigizieyeshaw29@gmail.com

${ }^{1}$ Department of Physiology, School of Medicine, College of Medicine and Health Sciences, University of Gondar, P. O. Box 196, Gondar, Ethiopia ${ }^{2}$ Department of Epidemiology and Biostatistics, Institute of Public Health, College of Medicine and Health Sciences, University of Gondar, P. O. Box 196, Gondar, Ethiopia

Full list of author information is available at the end of the article
}

(c) The Author(s). 2020 Open Access This article is licensed under a Creative Commons Attribution 4.0 International License, which permits use, sharing, adaptation, distribution and reproduction in any medium or format, as long as you give appropriate credit to the original author(s) and the source, provide a link to the Creative Commons licence, and indicate if changes were made. The images or other third party material in this article are included in the article's Creative Commons licence, unless indicated otherwise in a credit line to the material. If material is not included in the article's Creative Commons licence and your intended use is not permitted by statutory regulation or exceeds the permitted use, you will need to obtain permission directly from the copyright holder. To view a copy of this licence, visit http://creativecommons.org/licenses/by/4.0/ The Creative Commons Public Domain Dedication waiver (http://creativecommons.org/publicdomain/zero/1.0/) applies to the data made available in this article, unless otherwise stated in a credit line to the data. 


\begin{abstract}
(Continued from previous page)
Conclusions: Household iodized salt utilization had significant spatial variation across the country. Both household and community level variables were found to be associated with household iodized salt utilization in Ethiopia. Therefore, increasing the education level, wealth status and community media exposure is recommended to improve iodized salt utilization in a country. A targeted intervention is also needed for those regions with low household iodized salt utilization.
\end{abstract}

Keywords: lodized salt utilization, Spatial analysis, Multilevel analysis, Ethiopia

\section{Background}

Iodine is an essential micronutrient used for the synthesis of thyroid hormones, which are vital for body growth, development and control of metabolic processes in the body $[1,2]$. Inadequate iodine utilization results in iodine deficiency disorder (IDD) [3], the most important preventable cause of brain damage worldwide [4-6]. The problem is pronounced for pregnant women and young children that creates a threat to the social and economic development of countries [6]. Iodine deficiency disorder can start before birth; threaten children's mental health and their very survival. It affects body growth and mental development leading to learning disability, irreversible mental retardation, reduce school performance, poor productivity, unemployment and an increased risk of mortality [7]. Even mild iodine deficiency during pregnancy can have long-term adverse impacts on fetal cognition that are not improved by sufficient iodine intake during childhood [8-12].

Although substantial progress has been made over the last decades, worldwide, iodine deficiency remains a significant health problem; affecting both developed and developing nations [13]. Globally more than 1.88 billion people have insufficient iodine intake [14]. In Africa, over 330 million people remain at continued risk of IDD [15] and the problem is more pronounced in subSaharan Africa including Ethiopia [16]. In Ethiopia, the prevalence of household iodized salt utilization is $15 \%$ in 2011 [17] and 89\% in 2016 [18].

Several factors are known to affect iodized salt utilization. Most importantly, being female, married [19, 20], having knowledge on IDD and iodized salt [19, 2125], higher educational status [24, 26-28], and higher monthly income $[26,27,29]$ are significantly associated with iodized salt utilization.

Iodization of salt has been proven to be the most effective strategy to provide populations with iodine and prevent IDD [30]. Hence, Ethiopia has launched mandatory salt iodization program in 2011 [31] and notable progress have made towards universal salt iodization [32]. However, still it is under the recommendation of World Health Organization (90\%) [4] and its coverage and utilization varies from region to region [32, 33]. For instance, the coverage of iodized salt is lowest in Somali and Afar regions, but highest in others [18].
Despite the problem, to the best of our knowledge, there is no study that investigates the spatial distribution and determinant factors of iodized salt utilization in Ethiopia at the national level. This research is important for both policy makers and health professionals to implement targeted intervention for the problem; by identifying areas which are more affected by the problem.

\section{Methods}

\section{Study area and data source}

The study was conducted based on secondary data, Ethiopian Demographic and Health Survey 2016 (EDHS 2016). The EDHS is a survey conducted every five years in Ethiopia [18], a country found in East Africa $\left(3^{\circ}-14^{\circ}\right.$ $\mathrm{N}$ and $33^{\circ}-48^{\circ} \mathrm{E}$ ), with 9 regional states (Oromia, Afar, Gambella, Benishangul-Gumuz, Amhara, Harari, Southern Nations, Nationalities and People's (SNNP), Somali and Tigray), and two city administrations (Addis Ababa and Dire Dawa). Each region is divided into zones and the zones are again divided into Woredas. Woredas are further divided into kebeles, the smallest administrative units of the country.

The present study used the recent Ethiopian Demographic and Health Survey 2016 (EDHS 2016) aiming to determine the spatial distribution and determinants of iodized salt utilization in Ethiopia. Ethiopia Demographic Health Survey (EDHS) provides population and health indicators at the national and regional levels.

\section{Sample size, sampling procedure and data collection}

The sampling frame used for the 2016 EDHS is the Ethiopia Population and Housing Census (PHC), which was conducted in 2007 by the Ethiopia Central Statistical Agency. The census frame is a complete list of 84,915 enumeration areas (EAs) created for the 2007 PHC. The EDHS used a two-stage stratified cluster sampling method. Stratification was done by separating the nine regional states and the two city administrations of Ethiopia, into urban and rural areas, with the exception of Addis Ababa (entirely urban). Each stratum was further divided into smaller units called enumeration areas or clusters (a geographic area consisting of 200-300 households), using the list of all clusters prepared by the 2007 
Population and Housing Census (PHC) as a sampling frame. A total of 645 enumeration areas (EAs) were selected in the first stage (of which, 202 were from urban areas) using probability proportional to EA size and with independent selection in each sampling stratum. In the second stage of selection, a fixed number of 28 households per cluster were selected with an equal probability systematic selection from the newly created household listing. Data were collected by trained data collectors using a pretested structured, interviewer-administered questionnaire [18]. Households having salts in their house and tested for iodine were included. Accordingly, total weighted samples of 15,891 households were included in the study.

\section{Variables of the study}

The outcome variable for this study was household iodized salt utilization which is dichotomized as yes (iodized) or no (not iodized). To assess the use of iodized salt, households were asked to provide a teaspoon of salt used for cooking and the salt was tested for iodine using the iodine rapid test kit [18]. Iodine rapid test kits (RTKs), can accurately distinguish between iodized and non-iodized salt and only be used to measure the percentage of salt that contains any iodine at all.

The independent variables for this study include both individual and community level factors. The individual level variables were: age of the household head, marital status, education level, wealth index, media exposure (it is a composite of reading newspaper, listening radio and watching television. By aggregating these variables we generated media exposure and recoded as yes "if a women has exposure to either of the three media sources" and no "if a women didn't have exposure to all of the three media sources") and residence; whereas community education level, community poverty level and community media exposure were the community level variables. The last three community-level factors were not directly found in the EDHS data; created by aggregating the selected individual level factors at the cluster level and categorized as high and low based on the median value; their value was skewed.

\section{Data analysis procedure}

We used ArcGIS version 10.6 and Spatial Scan Statistics (SaTScanTM version 9.6) software's to perform the spatial data analysis. Global Moran's index (Moran's I) was used to determine the presence of spatial autocorrelation. Hot-spot analysis was done using Getis-Ord $\mathrm{Gi}^{*}$ statistics. Spatial interpolation was also done to predict the iodized salt utilization in unmeasured areas based on the values from sampled data. Spatial scan statistics was done to identify significant primary (most likely) and secondary clusters. SaTScan $^{\text {tw }}$ works with a moving window and requires fixing of the window size that moves across the study area. The outcome variable has Bernoulli distribution so Bernoulli model was used by applying the Kuldorff method for purely spatial analysis. Households who were utilized iodized salt were taken as cases and those who did not take were taken as controls to fit the Bernoulli model. The default maximum spatial cluster size of $<50 \%$ of the population was used as an upper limit, which allowed both small and large clusters to be detected and ignored clusters that contained more than the maximum limit. Areas with high Log Likelihood Ratio and significant $p$ value were considered as areas with high iodized salt utilization compared to areas outside of the window.

To identify the determinant factors of household iodized salt utilization, STATA 14 software was used. The data were weighted before doing any statistical analysis. In EDHS, some of the regions are oversampled and some are under sampled. Therefore, we have used weighted data to restore the representativeness of the sample. Moreover, weighting for design was also done to get a reliable estimate and standard error. The whole procedure of weighting was made based on the guide of DHS statistics [34]. Since the EDHS data has hierarchical nature, measures of community variation/randomeffects (Intraclass Correlation Coefficient, Median Odds Ratio and Proportional Change in Variance) were estimated. The values of these measures were significant, indicating the use of multilevel logistic regression model than ordinary logistic regression. Model comparison was done using deviance between the nullmodel (a model with no independent variable), model I (a model with only individual-level factors), model II (a model with community-level factors) and model III (a model that contain both individual and community level independent variables). A model with the lowest Deviance (model III) was the best fitted model. Both bivariable and multivariable multilevel logistic regression was performed to identify the determinant factors of household iodized salt utilization in Ethiopia. All variables with a $\mathrm{p}$ value $<0.25$ at bi-variable multilevel logistic model analysis were entered into the multivariable multilevel logistic regression model. $P$ value $\leq 0.05$ was used to declare statistically significant variables in the final model.

\section{Results}

\section{Sociodemographic characteristics}

Weighted sample of 15,891 households were included in this study. The majority, $12,731(80 \%)$ of the households 
were rural. The mean age of household head was 44.38 years $( \pm 16.10 \mathrm{SD})$. More than half, $8703(54.77 \%)$ of the households had no education. The majority $(71.53 \%)$ of the households had no radio. Regarding marital status, more than three fourth $(77.33 \%)$ of the households were currently married. Eight thousand three hundred and four $(52.25 \%)$ of them were from low community education. Eight thousand three hundred and eleven (52.30\%) of them were from community with high poverty level (Table 1).

\section{Spatial analysis of household iodized salt utilization}

The overall iodized salt utilization in Ethiopia was 89.27\% (95\% CI $=88.78-89.74 \%)$. Among regions, Benishangul had the highest prevalence of household iodized salt utilization (94.14\%); whereas the lowest was in Somali region (62.45\%). The spatial distribution of household iodized salt utilization in Ethiopia was non-random (Global Moran's I $=0.076, \mathrm{p}$ value $=0.01$ ) (Fig. 1 ). The highest prevalence of household iodized salt utilization was identified in the Amhara, Tigray, Benishangul Gumuz, Gambela, Oromia and central SNNPRs regions whereas low iodized salt utilization was located in the entire Afar and Somali regions (Fig. 2).

The Getis Ord Gi statistical analysis shows the hotspot and cold spot areas of household iodized salt utilization in Ethiopia. The red colors indicates the significant hotspot areas (higher rates of household iodized salt utilization), which was found in the central and southern parts of Amhara, Northeast part of Benishangul-Gumuz, Addis Ababa, Southwest Oromia and West Gambella regions. In contrast, the blue color indicates significant cold spot areas (areas with low iodized salt utilization), found in Somali, and East Afar regions (Fig. 3). In the SaTScan analysis, a total of 364 significant clusters were identified. Of these, 304 were primary clusters. The primary clusters were located in the entire Benishangul, Amhara, Gambella, Tigray and Northwest Oromia regions, centered at $11.340042 \mathrm{~N}, 35.126734 \mathrm{E}$ with $509.53 \mathrm{~km}$ radius, a Relative Risk (RR) of 1.15, and Log-Likelihood Ratio (LRR) of 225.9, at $p$-value $<0.001$. Households within the spatial window had 1.15 times higher odds of utilizing iodized salt compared to those households outside the spatial window (Table 2). The secondary clusters were located in Southwest Oromia, eastern SNNPR, Dire Dawa, Harari, and Southwest Somali regions (Fig. 4).

In the Kriging interpolation, central, eastern and Southern parts of Amhara, north and southwest parts of Oromia and eastern part of Benishangul have predicted areas of high household iodized salt utilization compared to other regions. In contrast, predicted
Table 1 Sociodemographic characteristics of respondents in Ethiopia, 2016

\begin{tabular}{|c|c|c|}
\hline Variables & Weighted frequency & Percent \\
\hline \multicolumn{3}{|l|}{ Residence } \\
\hline Urban & 3160 & 20.00 \\
\hline Rural & 12,731 & 80.00 \\
\hline \multicolumn{3}{|l|}{ Age (years) } \\
\hline$<25$ & 905 & 5.69 \\
\hline $25-34$ & 3957 & 24.90 \\
\hline $35-44$ & 3747 & 23.58 \\
\hline $45-54$ & 2594 & 16.33 \\
\hline $55-64$ & 2352 & 14.80 \\
\hline 65 and above & 2336 & 14.70 \\
\hline \multicolumn{3}{|l|}{ Sex of household head } \\
\hline Male & 11,821 & 74.39 \\
\hline Female & 4070 & 25.61 \\
\hline \multicolumn{3}{|l|}{ Marital status } \\
\hline Never married & 649 & 4.08 \\
\hline Currently married & 12,288 & 77.33 \\
\hline Formerly married & 2954 & 18.59 \\
\hline \multicolumn{3}{|l|}{ Educational status } \\
\hline No education & 8703 & 54.77 \\
\hline Primary education & 4849 & 30.52 \\
\hline Secondary education & 1250 & 7.87 \\
\hline Higher education & 1089 & 6.85 \\
\hline \multicolumn{3}{|l|}{ Wealth index } \\
\hline Poorest & 3001 & 18.89 \\
\hline Poorer & 3067 & 19.30 \\
\hline Middle & 3032 & 19.08 \\
\hline Richer & 2992 & 18.83 \\
\hline Richest & 3799 & 23.91 \\
\hline \multicolumn{3}{|l|}{ Media exposure } \\
\hline Yes & 4525 & 28.47 \\
\hline No & 11,366 & 71.53 \\
\hline \multicolumn{3}{|c|}{ Community education level } \\
\hline Low & 8304 & 52.25 \\
\hline High & 7587 & 47.75 \\
\hline \multicolumn{3}{|l|}{ Community poverty level } \\
\hline Low & 7580 & 47.70 \\
\hline High & 8311 & 52.30 \\
\hline \multicolumn{3}{|c|}{ Community media exposure level } \\
\hline Low & 8151 & 51.29 \\
\hline High & 7740 & 48.71 \\
\hline
\end{tabular}




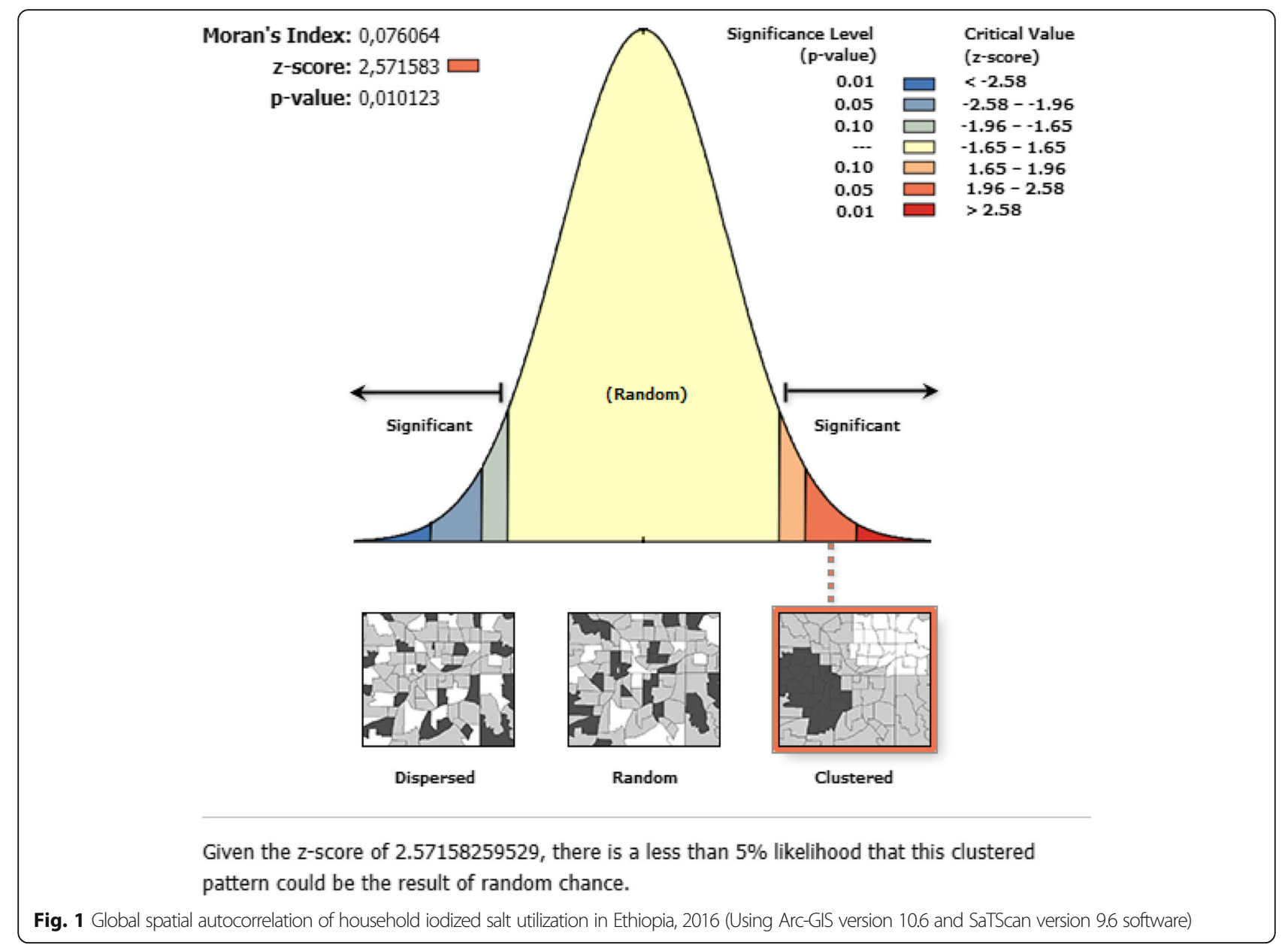

lower household iodized salt utilization areas were found in eastern Afar and Somali regions (Fig. 5).

\section{Random effect analysis}

The results of the random-effects model indicated that there was significant clustering of household iodized salt utilization across the communities (OR of community level variance $=3.442,95 \% \mathrm{CI}=2.905$ 4.078). The intra-class correlation (ICC) in the null model indicated that $51.1 \%$ of the overall variability of household iodized salt utilization was attributed to cluster variability. The median odds ratio (MOR) for household iodized salt utilization was 5.82 in the null model, which indicates that there was a variation in iodized salt utilization between clusters. This means if we randomly select households from different clusters, households at the cluster with higher household iodized salt utilization had 5.82 times higher odds of iodized salt use as compared with those households at cluster with lower iodized salt use. The Proportional Change in Variance (PCV) also increases from 6.3\% from model I to $9.4 \%$ in model III (a model with individual and community level variables), which indicates the last model (model III) best explains the variability of household iodized salt utilization, Besides, model fitness was checked using deviance and the model with the lowest deviance (model III) was the best fitted model (Table 3). Moreover, the predictive ability of these models was checked using Receiver Operating Curve (AUC), plotted based on sensitivity and 1 - specificity. Accordingly, the Area Under the ROC curve for model III was the highest (62.3\%), Therefore, incorporating the community level variables has improved the model.

\section{Determinants of household iodized salt utilization in Ethiopia}

On bivariable multilevel logistic regression analysis, education level, wealth index, media exposure, residence, community education level, community poverty level, and community media exposure level were associated with household iodized salt utilization $(p<$ 


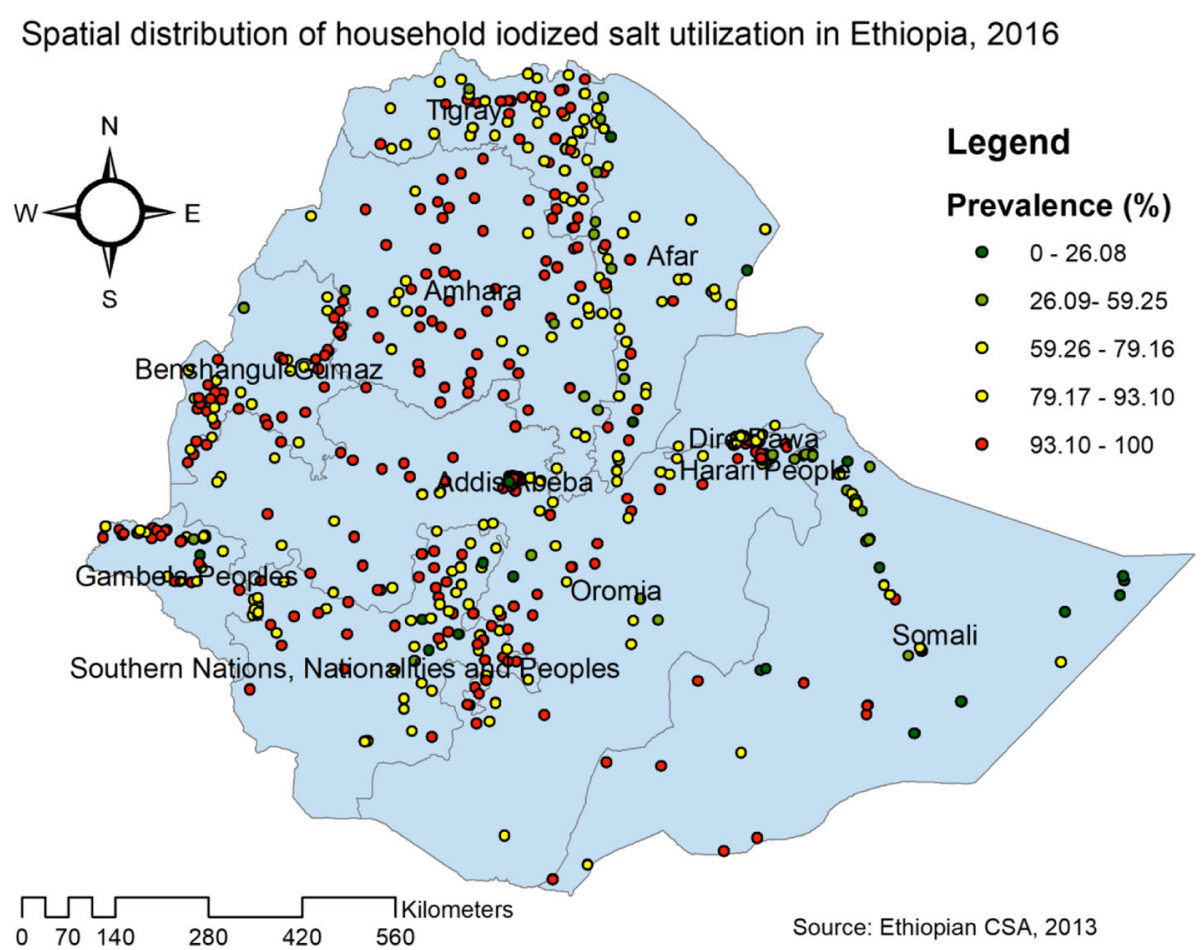

Fig. 2 Spatial distribution of household iodized salt utilization across regions in Ethiopia, 2016 (Using Arc-GIS version 10.6 and SaTScan version 9.6 software)

0.25). Therefore, these variables were eligible for the multivariable multilevel logistic regression/final model. Accordingly, wealth index, education level, community media exposure level and community education level were significantly associated with household iodized salt utilization in Ethiopia $(p \leq 0.05)$.

The odds of iodized salt utilization among the households with higher education level were 1.5 times higher compared with those who had no education (AOR = $1.49,95 \% \mathrm{CI}=1.14-1.93)$. Those households who were from high community education level had 1.5 times higher chance of iodized salt utilization compared with households of low community education level $(\mathrm{AOR}=$ $1.51,95 \% \mathrm{CI}=1.03-2.20$ ). The odds of household iodized salt utilization was 1.3 times higher among households with middle wealth index compared with the poorest once $(\mathrm{AOR}=1.31,95 \% \mathrm{CI}=1.04-1.65)$. The odds of iodized salt utilization among households with high community media exposure level was 1.5 times higher compared with households from low community media exposure level $(\mathrm{AOR}=1.52,95 \% \mathrm{CI}=1.07-2.17$ ) (Table 4).

\section{Discussion}

This study aimed to explore the spatial distribution and determinant factors of household iodized salt utilization in Ethiopia. Accordingly, we found that household iodized salt utilization in Ethiopia was clustered and affected by different factors.

The spatial distribution of household iodized salt utilization in Ethiopia was none random. The significant hotspot areas with high iodized salt utilization were located in entire Benishangul, Amhara, Gambella, Tigray and Northwest Oromia regions. In contrast, lower household iodized salt utilization was observed in Somali and Afar regions indicating the need to increase iodized salt coverage and so its utilization with strong collaboration between the governments, salt processing industries, supporting organizations and the community. The possible reason for this observed non-random distribution of iodized salt in the country might be due to the differences in access to non-iodized salt sources (high in Afar and Somali regions) [35], post fortification loss, and distance from fortification site. Another probable justification for this non-random distribution of iodized salt utilization could be the difference in education level of the households. In this study, only 106 (22.94\%) of Somali, and 37 (27.94\%) of Afar households have primary and above education, which is lower than other regional states of Ethiopia. This low educational status of the two regions might lead to low prevalence 


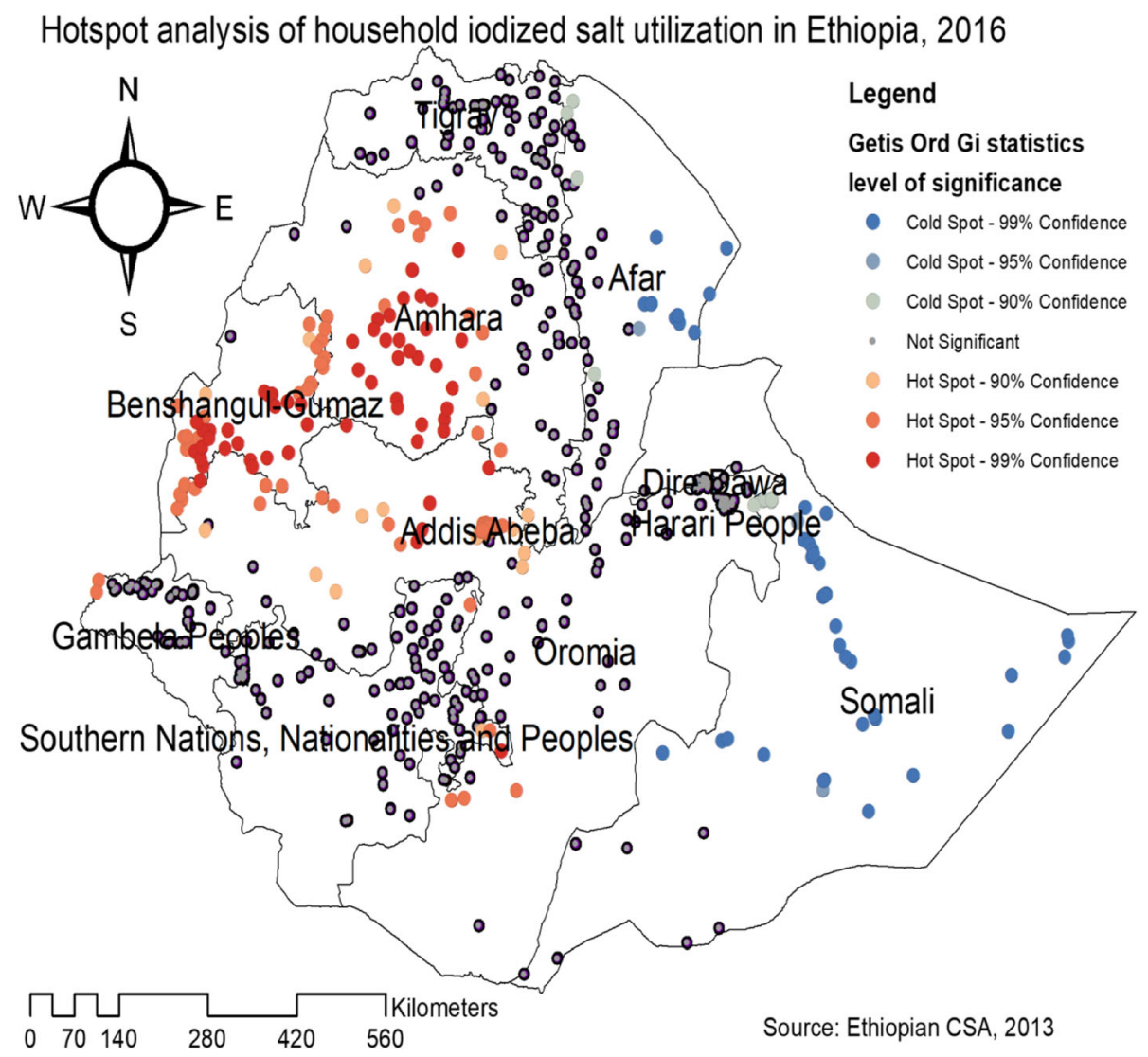

Fig. 3 Getis Ord Gi statistical analysis of hotspot areas of household iodized salt utilization in Ethiopia, 2016 (Using Arc-GIS version 10.6 and SaTScan version 9.6 software)

of household iodized salt utilization in these regions. This is because low education level is usually associated with low level of community awareness on prevention of IDDs, the benefits of iodized salt and its utilization $[26,27]$.

In this study, wealth index, education level, community education level and community media exposure level were significantly associated with higher odds of household iodized salt utilization in Ethiopia ( $\mathrm{p} \leq$ 0.05). The odds of iodized salt utilization among households with higher education level were 1.5 times higher compared with those who had no education. Similarly, those households who were from high community education level had higher chance of iodized salt use compared with households from low community education level. This finding is similar with the finding of other studies in Ethiopia [24, 26-28]. This could be due to participants who had education are more likely to be knowledgeable on the use of iodized salt than those who did not have education [26, 3638]. Moreover, households who had education usually had employment opportunities that might lead to relatively better socioeconomic status to purchase and use iodized salt compared to those households with no education.

Respondents' wealth index status is also associated with household iodized salt utilization in Ethiopia. The odds of iodized salt utilization among households with middle wealth index were higher compared with the poorest once. Our finding is consistent with the finding of many other studies in Ethiopia [19, 26, 27, 29]. This might be due to the reason that those households with poorest wealth index are facing economic constraint for buying iodized salt; iodized salt is less likely to be found in poor households due to its relatively higher cost [39].

Another factor associated with households iodized salt utilization in this study is level of community media exposure. The odds of iodized salt utilization among households with high community media exposure level were $52 \%$ times higher compared with households from low community media exposure level. The current finding is in line with a study in Turkey [37]. This is due to those households who had media exposure usually have more information about their health including the 
Table 2 Significant SaTScan clusters of areas with high proportion of household iodized salt use in Ethiopia, 2016

\begin{tabular}{|c|c|c|c|c|c|c|c|}
\hline clusters & Enumeration areas (EAs)/ clusters detected & $\begin{array}{l}\text { Coordinates/ } \\
\text { radius }\end{array}$ & Population & Cases & RR & LLR & $\begin{array}{l}\mathrm{P} \text { - } \\
\text { value }\end{array}$ \\
\hline $\begin{array}{l}1 \text { (number } \\
\text { of clusters) }\end{array}$ & $\begin{array}{l}256,457,35,364,137,324,244,386,415,285,183,569,409,209,36,548, \\
407,533,559,541,563,246,150,615,65,595,602,515,498,581,259,335, \\
508,433,203,317,6,165,184,52,124,416,88,621,17,320,361,374,109, \\
349,395,462,494,70,516,3,275,292,431,304,193,279,382,169,643, \\
73,175,161,429,167,248,375,158,474,403,294,24,163,640,512,456, \\
638,558,132,280,504,531,120,327,218,296,312,399,152,612,63,411, \\
549,47,291,469,114,221,322,482,229,206,231,315,234,350,346,105, \\
106,69,38,426,555,343,567,603,448,104,260,592,253,199,627,233, \\
370,507,265,628,80,309,62,258,517,536,176,118,435,266,593,545, \\
219,485,10,23,618,510,586,119,460,425,267,177,446,13,270,188, \\
284,326,417,583,432,340,66,554,423,46,262,268,591,572,489,299, \\
542,551,401,354,98,526,142,243,617,459,552,616,465,168,255,181, \\
371,197,174,478,528,274,78,486,154,76,11,339,463,147,477,107, \\
145,91,31,532,100,447,369,626,584,487,608,112,314,108,144,645, \\
207,59,195,300,635,170,305,153,464,414,582,15,159,110,227,247, \\
639,302,225,293,579,156,19,61,264,261,437,475,428,155,451,509, \\
539,287,560,330,502,575,211,139,90,577,402,252,136,236,410,636, \\
83,597,353,392,204,400,217,325,18,359,538,200,303,310,496,590, \\
97,424,143,455,81,351,223,271,449,611,331,345,442,40,376\end{array}$ & $\begin{array}{l}(11.340042 \mathrm{~N}, \\
35.126734 \mathrm{E}) / \\
509.53 \mathrm{~km}\end{array}$ & 7522 & 6923 & 1.15 & 225.9 & $\begin{array}{l}p< \\
0.001\end{array}$ \\
\hline 2 & $\begin{array}{l}422,34,316,398,405,468,600,232,21,518,445,313,32,182,576,574, \\
377,634,215,365,12,216,408,26,148,308,391,289,589,578,50\end{array}$ & $\begin{array}{l}(5.844300 \mathrm{~N} \\
39.182881 \mathrm{E}) / \\
170.92 \mathrm{~km}\end{array}$ & 790 & 759 & 1.12 & 45.6 & $\begin{array}{l}p< \\
0.001\end{array}$ \\
\hline 3 & $\begin{array}{l}610,383,329,238,495,381,443,173,396,60,393,288,614,28,228,157 \\
397,56,387,257,419,357,534,44,473,179,58,418,29\end{array}$ & $\begin{array}{l}(9.370004 \mathrm{~N} \\
42.102751 \mathrm{E}) / \\
7.94 \mathrm{~km}\end{array}$ & 698 & 661 & 1.1 & 28.1 & $\begin{array}{l}p< \\
0.001\end{array}$ \\
\hline 4 & 341,226 & $\begin{array}{l}(14.041828 \mathrm{~N}, \\
39.537923 \mathrm{E}) / \\
14.42 \mathrm{~km}\end{array}$ & 53 & 53 & 1.16 & 7.9 & $\begin{array}{l}P= \\
0.166\end{array}$ \\
\hline 5 & 208,520 & $\begin{array}{l}(4.006703 \mathrm{~N} \\
41.599741 \mathrm{E}) / \\
53.81 \mathrm{~km}\end{array}$ & 46 & 46 & 1.16 & 6.1 & $\begin{array}{l}P= \\
0.397\end{array}$ \\
\hline 6 & 1,566 & $\begin{array}{l}(9.505470 \mathrm{~N} \\
42.438628 \mathrm{E}) / \\
5.85 \mathrm{~km}\end{array}$ & 54 & 53 & 1.14 & 4.9 & $\begin{array}{l}P= \\
0.893\end{array}$ \\
\hline 7 & 166,311 & $\begin{array}{l}(9.510583 \mathrm{~N} \\
41.898978 \mathrm{E}) / \\
5.60 \mathrm{~km}\end{array}$ & 51 & 50 & 1.14 & 4.5 & $\begin{array}{l}P= \\
0.966\end{array}$ \\
\hline 8 & $476,506,412,122,333,245,372$ & $\begin{array}{l}(8.888553 \mathrm{~N} \\
40.744565 \mathrm{E}) / \\
62.70 \mathrm{~km}\end{array}$ & 174 & 162 & 1.08 & 4.3 & $\begin{array}{l}P= \\
0.983\end{array}$ \\
\hline
\end{tabular}

importance of iodized salt compared to households without media exposure. This finding implies that health education through mass media such as radio has been effective in promoting the use of iodized salt especially in rural communities [40]. This would be more effective for countries like Ethiopia, a country where more than $80 \%$ of its population is rural in resident and had no access to use latest mass media types.

This study has the following strengths. Firstly, we used multilevel model, a model that accounts the hierarchical nature of the data to get reliable estimates. The second strength of this study is the use of nationally representative data which can have greater power of generalizability. As limitation, this study uses rapid test kits (RTKs) essential only to determine the presence or absence of iodine, are non-quantitative. Therefore, we are unable to determine the quality of salt iodization and its spatial distribution in the country.

\section{Conclusions}

Household iodized salt utilization had significant spatial variation across the country. Benishangul-Gumz, Amhara, Gambella, Tigray and Northwest Oromia regions were the significant hotspot areas with high iodized salt utilization. Households with higher education level, from high community education level and high community media exposure level and middle wealth index had higher odds of iodized salt utilization. Therefore, increasing education level, wealth status and community media exposure is recommended to improve iodized salt utilization. Moreover, targeted intervention is needed for Afar and Somali regions, areas with low iodized salt utilization. 


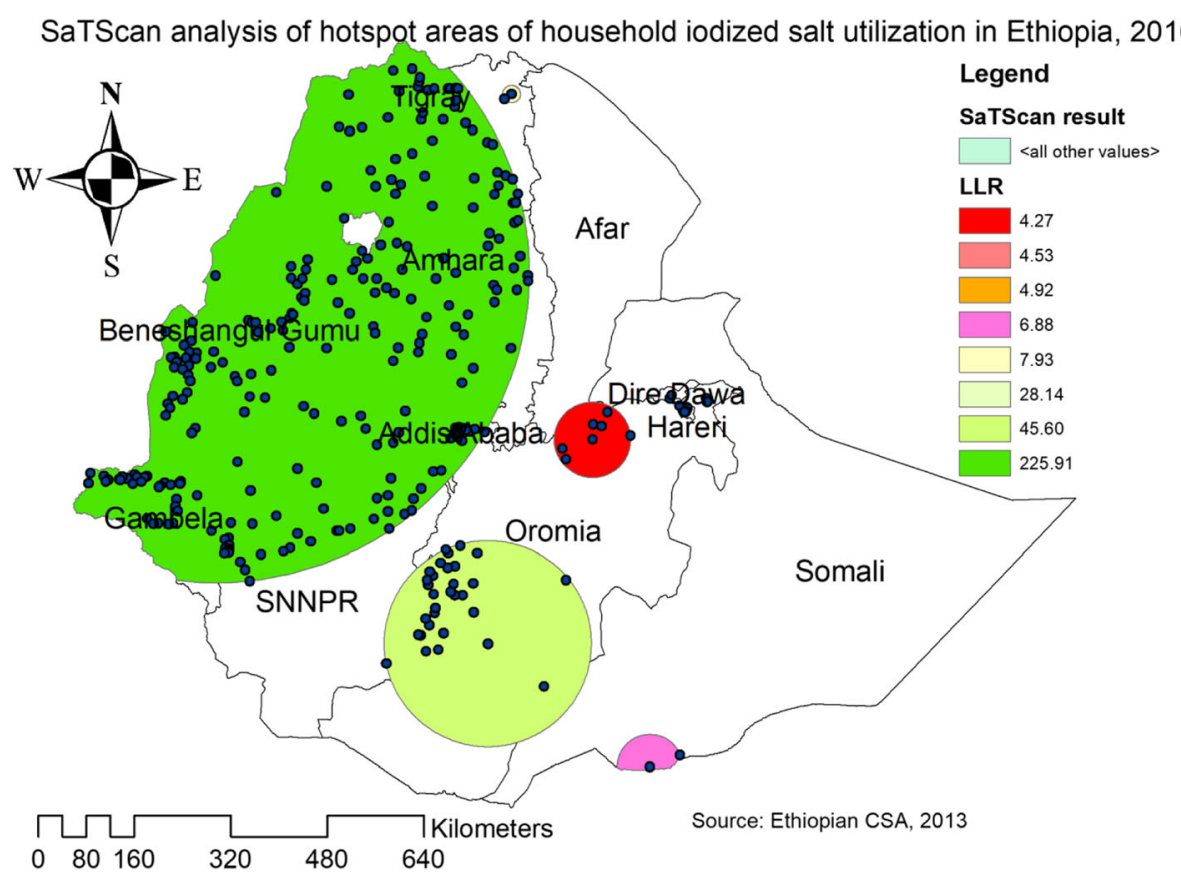

Fig. 4 SaTScan analysis of primary and secondary hotspot clusters of household iodized salt utilization in Ethiopia 2016 (Using Arc-GIS version 10.6 and SaTScan version 9.6 software)

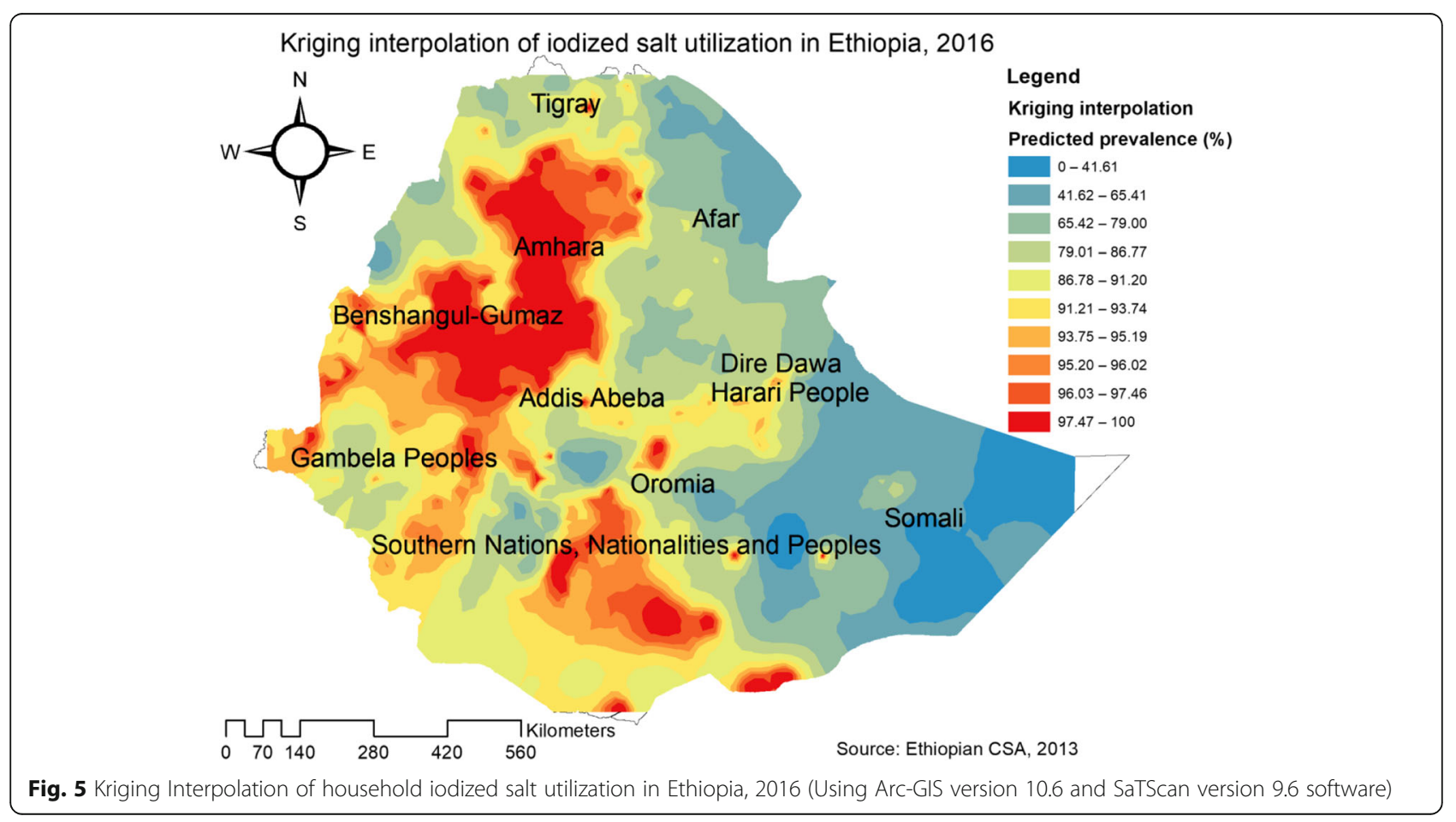


Table 3 Model comparison and random effect analysis result

\begin{tabular}{lllll}
\hline Parameters & Null model & Model I & Model II & Model III \\
\hline Community-level variance & 3.442 & 3.224 & 3.173 & 3.120 \\
ICC & $51.1 \%$ & $49.5 \%$ & $49.1 \%$ & $48.7 \%$ \\
MOR & 5.82 & 5.53 & 5.43 & 5.36 \\
PCV & Ref & $6.3 \%$ & $7.8 \%$ & $9.4 \%$ \\
Log likelihood & -5023.507 & -5003.621 & -5006.784 & -4995.235 \\
LR test & $X^{2}=2629.15 P<0.001$ & $X^{2}=2389.61$ & $X^{2}=2419.65$ & $X^{2}=2334.39$ \\
& & $P<0.001$ & $P<0.001$ & $P<0.001$ \\
Deviance & $10,047.01$ & $10,007.242$ & $10,013.568$ & 9990.470 \\
\hline
\end{tabular}

Table 4 Multilevel logistic regression analysis of household iodized salt utilization in Ethiopia, 2016

\begin{tabular}{|c|c|c|c|c|}
\hline \multirow[t]{2}{*}{ Variables } & \multicolumn{2}{|c|}{ Use of iodized salt } & \multicolumn{2}{|l|}{ Odds ratio } \\
\hline & $\begin{array}{l}\text { Yes } \\
N(\%)\end{array}$ & $\begin{array}{l}\text { No } \\
\text { N (\%) }\end{array}$ & $\begin{array}{l}\text { COR } \\
(95 \% \mathrm{Cl})\end{array}$ & $\begin{array}{l}\text { AOR } \\
(95 \% \mathrm{Cl})\end{array}$ \\
\hline \multicolumn{5}{|c|}{ Community media exposure level } \\
\hline low & $7127(50.24)$ & $1024(60.08)$ & 1 & 1 \\
\hline High & 7059 (49.76) & 681 (39.92) & $2.14(1.57-2.91)$ & $1.52(1.07-2.17)^{*}$ \\
\hline \multicolumn{5}{|l|}{ Residence } \\
\hline Rural & $11,284(88.63)$ & $1447(11.37)$ & 1 & 1 \\
\hline Urban & 2902(91.84) & $258(8.16)$ & $1.81(1.29-2.55)$ & $0.82(0.50-1.35)$ \\
\hline \multicolumn{5}{|l|}{ Media exposure } \\
\hline Yes & $4120(91.06)$ & 405(8.94) & $1.21(1.10-1.38)$ & $1.10(0.95-1.26)$ \\
\hline No & $10,066(88.56)$ & $1300(11.44)$ & 1 & 1 \\
\hline \multicolumn{5}{|l|}{ Education level } \\
\hline No education & $7734(88.87)$ & 969 (11.13) & 1 & 1 \\
\hline $1^{\text {ry }}$ education & $4312(88.92)$ & $537(11.08)$ & $1.10(0.95-1.24)$ & $1.02(0.89-1.17)$ \\
\hline $2^{\text {ry }}$ education & $1119(89.56)$ & $131(10.44)$ & $1.39(1.12-1.74)$ & $1.25(0.99-1.57)$ \\
\hline Higher education & $1021(93.73)$ & $68(6.27)$ & $1.68(1.30-2.16)$ & $1.49(1.14-1.93)^{*}$ \\
\hline \multicolumn{5}{|c|}{ Community education } \\
\hline Low & 7419 (89.35) & $885(10.65)$ & 1 & 1 \\
\hline High & 6767(89.19) & $820(10.81)$ & $2.16(1.59-2.94)$ & $1.51(1.03-2.20)^{*}$ \\
\hline \multicolumn{5}{|l|}{ Community poverty } \\
\hline High & 7455 (89.71) & $855(10.29)$ & $1.99(1.46-2.71)$ & $1.20(0.78-1.84)$ \\
\hline Low & $6731(88.79)$ & $850(11.21)$ & 1 & 1 \\
\hline \multicolumn{5}{|l|}{ Wealth index } \\
\hline Poorest & 2577 (85.86) & $424(14.14)$ & 1 & 1 \\
\hline Poorer & $2762(90.07)$ & $305(9.93)$ & $1.22(0.99-1.49)$ & $1.15(0.94-1.41)$ \\
\hline Middle & $2711(89.40)$ & $321(10.60)$ & $1.45(1.16-1.81)$ & $1.31(1.04-1.65)^{*}$ \\
\hline Richer & $2672(89.29)$ & $320(10.71)$ & $1.49(1.18-1.88)$ & $1.26(0.99-1.62)$ \\
\hline Richest & $3465(91.21)$ & 334 (8.79) & 1.79 (1.39-2.29) & $1.26(0.92-1.73)$ \\
\hline
\end{tabular}




\section{Abbreviations}

AOR: Adjusted Odds Ratio; Cl: Confidence Interval; COR: Crude odds ratio; EDHS: Ethiopian Demographic and Health Survey; ICC: Intraclass Correlation Coefficient; IDD: lodine Deficiency Disorder; MOR: Median Odds Ratio; PCV: Proportional Change in Variance

\section{Acknowledgments}

We would like to thank the MEAUSRE DHS for providing the data set for the study. We also appreciate the scientific writing provided by Baye Dagnew.

\section{Authors' contributions}

YY conceived and designed the study, conducted data analysis, interpret the data and drafted the manuscript for publication. GAT, ABT, AZA, AML, and AKT analyze and interpret the data, and reviewed the manuscript. All authors read and approved the final manuscript and agree to be accountable for all aspects of the work.

\section{Funding}

No specific funding

\section{Availability of data and materials}

All relevant data are included in the article. The Ethiopian Demographic and Health Survey data set used for the analysis was obtained from the link https://dhsprogram.com/data/dataset_admin/index.cfm, after reasonable request of the DHS Program.

\section{Ethics approval and consent to participate}

Permission to use the data was obtained from DHS Program. Procedures for DHS public-use datasets was approved by the Institution Review Board (IRB).

\section{Consent for publication}

Not applicable.

\section{Competing interests}

The authors declare that they have no competing interests.

\section{Author details}

${ }^{1}$ Department of Physiology, School of Medicine, College of Medicine and Health Sciences, University of Gondar, P. O. Box 196, Gondar, Ethiopia. ${ }^{2}$ Department of Epidemiology and Biostatistics, Institute of Public Health, College of Medicine and Health Sciences, University of Gondar, P. O. Box 196, Gondar, Ethiopia. ${ }^{3}$ Department of Health Education and Behavioral Science, Institute of Public Health, College of Medicine and Health Sciences, University of Gondar, P. O. Box 196, Gondar, Ethiopia.

Received: 11 May 2020 Accepted: 13 September 2020 Published online: 17 September 2020

\section{References}

1. National Inistitute of Health. lodine Fact Sheet for Consumers. 2020 Available from: https://ods.od.nih.gov/pdf/factsheets/lodine-Consumer.pdf.

2. Organization $\mathbf{W H}$. Vitamin and mineral requirements in human nutrition: World Health Organization; 2004.

3. $\mathrm{WHO}$. lodine defi ciency in Europe A continuing public health problem 2007

4. $\mathrm{WHO}, \mathrm{ICCIDD} \cup$. Assessment of iodine deficiency disorders and monitoring their elimination 3rd edn. Geneva: World Health Organisation; 2007. Available from: https:/apps.who.int/iris/bitstream/handle/10665/43781/ 9789241595827_eng.pdf;jsessionid=C62D6F03EEF16C2F521055CA5B1EB1D4 ?sequence $=1$.

5. Chung HR. lodine and thyroid function. Ann Pediatr Endocrinol Metab. 2014;19:8-12.

6. De Benoist B, Andersson M, Egli I, Takkouche B, Allen H. lodine status worldwide. WHO Global database on iodine deficiency. Geneva: World Health Organization; 2004.

7. Zerfu D. National salt iodization coverage towards prevention of iodine deficiency disorder in Ethiopia. Addis Ababa: Ethiopian Public Health Institute; 2014.

8. Hynes KL, Otahal P, Hay I, Burgess JR. Mild iodine deficiency during pregnancy is associated with reduced educational outcomes in the offspring: 9-year follow-up of the gestational iodine cohort. J Clin Endocrinol Metab. 2013;98(5):1954-62

9. Parameswaran GG, Yadav K. lodine status of pregnant women and cognitive outcomes of their children. Natl Med J India. 2017;27(3):1-3.

10. Bath SC, Steer CD, Golding J, Emmett P, Rayman MP. Eff ect of inadequate iodine status in UK pregnant women on cognitive outcomes in their children : results from the Avon longitudinal study of parents and children ( ALSPAC ). Lancet. 2013;6736(13):1-7. https://doi.org/10.1016/S01406736(13)60436-5.

11. Zhou SJ, Anderson AJ, Gibson RA, Makrides M. Effect of iodine supplementation in pregnancy on child development and other clinical outcomes : a systematic review of randomized. Am J Clin Nutr. 2013;98(2): 1241-54.

12. Caron P. Neurocognitive outcomes of children secondary to mild iodine deficiency in pregnant women. Ann Endocrinol (Paris). 2015;76(3):248-52. https://doi.org/10.1016/j.ando.2015.01.001.

13. Pearce EN, Andersson M, Zimmermann MB. Global iodine nutrition: where do we stand in 2013? Thyroid. 2013;23(5):523-8.

14. Andersson M, Karumbunathan V, Zimmermann MB. Global iodine status in 2011 and trends over the past decade. J Nutr. 2012;142:744-50.

15. Universal Salt lodisation in Africa: Road to overcoming the last Universal Salt lodisation in Africa . 2005. Available from: https://www.nutritionintl.org/ content/user_files/2017/06/Universal-Salt-lodisation-in-Africa-Road-toovercoming-the-last-hurdles.pdf.

16. Zimmermann MB, Jooste PL, Pandav CS. lodine-defi ciency disorders. Lancet. 2008;372:1251-62.

17. Central Statistical Agency [Ethiopia] and ICF International. Ethiopia Demographic and Health Survey. 2011.

18. Central Statistical Agency (CSA) [Ethiopia] and ICF. Ethiopia Demographic and Health Survey. 2016.

19. Hawas SB, Lemma S, Mengesha STDH. And SM. Proper utilization of Adequatly iodized salt at household level and associated Factores in Asella town Arsi zone Ethiopia : a community based cross sectional study. J Food Process Technol. 2016;7(4):1-8.

20. Alemu BM, Sciences M, Roba KT. Household salt iodine level and associated factors in Dire Dawa City. East African J Heal Biomed Sci. 2018;2(2):35-44.

21. Roba EH, KT. East African Journal of Sciences ( 2019 ) Utilization of lodized salt and Associated Factor in Zuway Dugda District, Arsi Zone, Oromia Regional State, South East Ethiopia. East African J Sci. 2019;13(1):75-80.

22. Abebe Z, Tariku A, Gebeye E. Availability of adequately iodized in Northwest Ethiopia: a cross-sectional study. Arch Public Health. 2017;75(33):1-9.

23. Gebremariam HG, Yesuf ME, Koye DN. Availability of adequately iodized salt at household level and associated factors in Gondar town. Northwest Ethiopia ISRN Public Health. 2013;2013:1-7.

24. Dida N, Legese A, Aman A, Muhamed B, Damise T, Birhanu T, et al. Availability of adequately iodised salt at household level and its associated factors in Robe town, Bale Zone, South East Ethiopia: community-based cross-sectional study. South Afr J Clin Nutr. 2020;33(3):58-63.

25. Berhane A, Baraki N, Endale BS. Availability of Adequately lodized Salt at Household Level and Associated Factors in Dire Dawa, Eastern. Int J ofPublic Heal Sci. 2016;5(4):392-9.

26. Tariku WB, Mazengia AL. Knowledge and utilization of iodized salt and its associated factors at household level in Mecha District. Northwest Ethiopia Nutr Metab. 2019;2019:1-9.

27. Bazezew MM, Yallew WW, Belew AK. Knowledge and practice of iodized salt utilization among reproductive women in Addis Ababa City. BMC Res Notes. 2018:11(1):734.

28. Kumma WP, Haji Y, Abdurahmen J, Adinew YM, Mehretie AY. Factors affecting the presence of adequately iodized salt at home in Wolaita. Southern Ethiopia: Community Based Study Int J food Sci. 2018;2018: 4394908.

29. Mekonnen TC, Eshete S, Yitbarek Wasihun MA, NC. Availability of adequately iodized salt at household level in Dessie and Combolcha towns, south Wollo, Ethiopia. BMC Public Health. 2018;18(1152):1-9.

30. Aburto N, Abudou M, Candeias V, Wu T. Effect and safety of salt iodization to prevent iodine deficiency disorders: a systematic review with metaanalyses. WHO eLibrary of Evidence for Nutrition Actions (eLENA). Geneva: World Health Organization; 2014.

31. Nutrition GA for I. Achieving Health Impact in Ethiopia through Salt Iodization : Progress to Date and GAIN's Role. 2015. 
32. Knowles JM, Garrett GS, Gorstein J, Kupka R, Situma R, Yadav K, et al. Household Coverage with Adequately lodized Salt Varies Greatly between Countries and by Residence Type and Socioeconomic Status within Countries: Results from 10 National Coverage Surveys 1-3. J Nutr. 2017; 147(2):1004S-14S.

33. Hailu A. Remarkable progress against iodine deficiency in Ethiopia. 2016 Available from: https://www.ign.org/newsletter/idd_aug17_ethiopia.pdf.

34. Croft, Trevor N., Aileen M. J. Marshall, Courtney K. Allen et al. Guide to DHS Statistics. 2018.

35. Alemu ZA, Teklu KT, Alemayehu TA, Balcha KH. Physicochemical quality of drinking water sources in Ethiopia and its health impact : a retrospective study. Environ Syst Res. 2015;4(22):1-8.

36. Buxton C, Baguune B. Knowledge and practices of people in Bia District Ghana, with regard to iodine deficiency disorders and intake of iodized salt. Arch Public Heal. 2012;70(1):5 Available from: http://www.archpublichealth com/content/70/1/5.

37. Green J. The role of local mass media in promoting the consumption of iodized table salt. Health Educ Res. 2001;16(5):603-7.

38. Lowe N, Westaway E, Munir A, Tahir S, Dykes F, Lhussier M, et al. Increasing awareness and use of iodised salt in a marginalised community setting in. Nutrients. 2015;7:9672-82.

39. Khan JR, Biswas RK, Sheikh MT, Huq M. Factors associated with the availability of iodized salt at household level: a case study in Bangladesh. Public Health Nutr. 2019;22(10):1815-23.

40. Khoja S, Luby S, Ahmed Z, Akber A, Health C, Khan TA. Effectiveness of Health Education in promoting the use of lodized salt in Lotkoh, Tehsil Chitral , Pakistan. JPMA. 2004;50(9):1-6.

\section{Publisher's Note}

Springer Nature remains neutral with regard to jurisdictional claims in published maps and institutional affiliations.

Ready to submit your research? Choose BMC and benefit from:

- fast, convenient online submission

- thorough peer review by experienced researchers in your field

- rapid publication on acceptance

- support for research data, including large and complex data types

- gold Open Access which fosters wider collaboration and increased citations

- maximum visibility for your research: over $100 \mathrm{M}$ website views per year

At $\mathrm{BMC}$, research is always in progress.

Learn more biomedcentral.com/submissions 